\title{
Seroimmunity to Tetanus and Diphtheria among Immunocompetent Adult Patients Admitted to a Tertiary Hospital for Any Reason
}

\author{
Hamid Reza Naderi' ${ }^{1}$, Fereshte Sheybani ${ }^{1}$, Bezat Amiri ${ }^{1}$, Mehdi Jabbari Nooghabi ${ }^{2}$ \\ ${ }^{1}$ Department of Infectious Diseases and Tropical Medicine, Mashhad University of Medical Sciences, Mashhad, Iran \\ ${ }^{2}$ Department of Statistics, Faculty of Mathematical Sciences, Ferdowsi University of Mashhad, Mashhad, Iran \\ Email: naderihr@mums.ac.ir
}

How to cite this paper: Naderi, H.R., Sheybani, F., Amiri, B. and Nooghabi, M.J. (2018) Seroimmunity to Tetanus and Diphtheria among Immunocompetent Adult Patients Admitted to a Tertiary Hospital for Any Reason. World Journal of Vaccines, $\mathbf{8}$, 21-29.

https://doi.org/10.4236/wjv.2017.81003

Received: January 4, 2018

Accepted: February 8, 2018

Published: February 11, 2018

Copyright $\odot 2018$ by authors and Scientific Research Publishing Inc. This work is licensed under the Creative Commons Attribution International License (CC BY 4.0).

http://creativecommons.org/licenses/by/4.0/

\begin{abstract}
Ignoring the importance of receiving booster doses of vaccines in vast majority of adults could result in their lack of immunity against tetanus and diphtheria. In this prospective cohort study all immunocompetent adults $\geq 40$ years old who were admitted for any reason during the time period of the survey were enrolled and antibody levels against tetanus and diphtheria were measured. 84 patients (48\%) were 40 - 60 years old and 93 (52\%) subjects aged older than 60 years. In general, anti-tetanus antibody titer was $<0.1 \mathrm{IU} / \mathrm{mL}$ (non-immune range) in 83 people (46.9\%). For anti-diphtheria antibody, 74 $(41.8 \%)$ were considered non-immune. Of all people whose tetanus antibody level was $<0.1,19$ had a complete history of childhood diphtheria and tetanus immunization and 64 had unknown vaccination history. Among people with diphtheria antibody levels $<0.1,18(24.3 \%)$ had complete history of childhood vaccination and 56 (75.6\%) had unknown history.
\end{abstract}

\section{Keywords}

Diphtheria-Tetanus Vaccine, Booster Immunization, Active Immunity

\section{Introduction}

Diphtheria and tetanus are serious diseases with considerable mortality that are preventable by immunization. According to the guidelines presented by the national immunization program in Iran, DPT vaccines, containing diphtheria, tetanus and pertussis toxoids are given at ages 2, 4, 6, 18 months and 6 years [1]. Booster immunization of adolescents and adults is recommended for long-term protective immunity against diphtheria and tetanus. In most countries, adult 
booster vaccine $(\mathrm{Td})$ is recommended every 10 years [2]. Tdap is similar to $\mathrm{Td}$ but also containing acellular pertussis antigens. Wherever it is available, adolescents 11 - 18 years of age (preferably at age $11-12$ years) and adults 19 and older should receive a single dose of Tdap [3]. Unfortunately, adults often neglect the need for booster vaccinations and these booster doses actually are not received every 10 years by most people. Nevertheless, some booster doses are mandatory due to local policies in different geographical regions. One study found the factors responsible for missed opportunities were: poor history taking, lack of knowledge of the current immunization schedule, dependence on physician referral for immunization and inefficient immunization records keeping system [4]. For example, in Iran all young women of childbearing age and all young men who are eligible to enter the military service should receive a booster dose of Td. But afterward, there is no health-care system to encourage them to receive booster dosing every ten years. Therefore, this study aims to measure protective levels of antibodies against diphtheria and tetanus in people over 40 years (e.g. at least 10 - 20 years after their last mandatory booster vaccination). If levels of antibodies against diphtheria and tetanus are found to be in non-immune range $(<0.1 \mathrm{IU} / \mathrm{mL})$ in the vast majority of subjects, it seems reasonable to suggest that a mandatory booster dose of $\mathrm{Td}$ should be considered for all patients older than 40 years who are admitted to hospital for any reason.

\section{Patients and Methods}

In this prospective cohort study, 177 immunocompetent adults $\geq 40$ years old admitted for any reason to the department of infectious diseases at a tertiary hospital during 2015 were enrolled. According to the national policies, all young women of childbearing age and all young men upon entering the military service should receive a mandatory dose of $\mathrm{Td}$ vaccine. Considering the fact that the majority of adults actually ignore to receive further booster doses of vaccine, it was assumed that people $\geq 40$ years old have possibly received their last dose of vaccine at most 10 - 20 years ago. So, they are old enough to determine whether they still have protective titers of antibodies against tetanus-diphtheria. The inclusion criteria were all immunocompetent people $\geq 40$ years old admitted for any reason to the department of infectious diseases during the study period, and the exclusion criteria were any person with a past or recent history of immunosuppression. The study was approved by Ethics Committee in Vice Chancellery of Research at Mashhad University of Medical Sciences and informed consent was obtained from all subjects. Serum samples were tested for tetanus and diphtheria IgG antibodies using enzyme-linked immunosorbent assay (ELISA) test (DRG Instruments GmbH, Germany, Division of DRG International Inc.).

\section{Results}

Out of 177 patients enrolled in this study, 98 (55\%) were male and 79 (45\%) were female. The subjects were divided into two age groups, $40-60$ years and 
older than 60 years. 84 patients (48\%) aged 40 - 60 and 93 (52\%) aged older than 60 years. $129(73 \%)$ of the subjects were urban residents and 48 (27\%) were from rural areas.

The subjects were divided into three groups according to their childhood tetanus and diphtheria vaccination history: complete, incomplete and uncertain. 49 people (27.7\%) had complete vaccination and 128 (72.3\%) had uncertain history. In general, 2 cases (1.1\%) received tetanus and diphtheria toxiod during the past 5 years, 7 (4\%) between 5 - 10 years and 168 (94.9\%) more than 10 years.

In the case of anti-tetanus antibody titer, four groups were considered: 83 people (46.9\%) had antibody levels less than 0.1, the level was $0.1-0.5$ in 42 cases $(23.7 \%)$, and $52(29.4 \%)$ had anti-tetanus antibody levels between 0.5 and 5 . None of the subjects had antibody levels above 5 .

In the case of anti-diphtheria antibodies, there were also four groups. Antibody levels less than 0.1 in 74 (41.8\%), $0.1-1$ in 93 (52.5\%) and 1 - 2 in 10 (5.6\%) subjects. None of those surveyed had antibody levels above 2.

The anti-tetanus and anti-diphtheria antibody levels according to age groups have been demonstrated in Table 1 .

According to Fisher's exact test, anti-tetanus antibody levels between age groups 40 - 60 years and above 60 years had no significant difference $(\mathrm{p}=0.189)$. However, of all people whose tetanus antibody level was less than 0.1, 19 had a complete history of childhood diphtheria and tetanus immunization and 64 had unknown vaccination history. According to the chi-square test, there was a significant difference between anti-tetanus antibody levels less than 0.1 and childhood tetanus-diphtheria immunization history $(\mathrm{p}<0.001)$. Likewise, out of 83 people with tetanus antibody levels less than 0.1 , one received $\mathrm{Td}$ vaccine during the past 5 years, one during 5 - 10 years and 81 (98.5\%) over 10 years, and according to the chi-square test, a significant difference was found between no immunity (antibody titers $<0.1$ ) and the time that has elapsed from receiving

Table 1. The anti-tetanus and anti-diphtheria antibody levels according to age groups of the patients.

\begin{tabular}{|c|c|c|c|c|c|c|c|c|c|c|}
\hline \multirow{2}{*}{$\begin{array}{l}\text { Age } \\
\text { range }\end{array}$} & \multicolumn{4}{|c|}{ Tetanus Antibody Titer ${ }^{*}$} & \multicolumn{5}{|c|}{ Diphtheria Antibody Titer ${ }^{\star *}$} & \multirow{2}{*}{ Total } \\
\hline & $<0.1$ & $0.1-0.5$ & $0.5-5$ & $>5$ & & $<0.1$ & $0.1-1$ & $1-2$ & $>2$ & \\
\hline $40-60$ & $\begin{array}{c}33 \\
39.3 \%\end{array}$ & $\begin{array}{c}25 \\
29.8 \%\end{array}$ & $\begin{array}{c}26 \\
31.0 \%\end{array}$ & 0 & 84 & $\begin{array}{c}34 \\
40.5 \%\end{array}$ & $\begin{array}{c}48 \\
57.1 \%\end{array}$ & $\begin{array}{c}2 \\
2.4 \%\end{array}$ & 0 & 84 \\
\hline$>60$ & $\begin{array}{c}50 \\
53.8 \%\end{array}$ & $\begin{array}{c}17 \\
18.3 \%\end{array}$ & $\begin{array}{c}26 \\
28.0 \%\end{array}$ & 0 & 93 & $\begin{array}{c}40 \\
43.0 \%\end{array}$ & $\begin{array}{c}45 \\
48.4 \%\end{array}$ & $\begin{array}{c}8 \\
8.6 \%\end{array}$ & 0 & 93 \\
\hline Total & $\begin{array}{c}83 \\
46.9 \%\end{array}$ & $\begin{array}{c}42 \\
23.7 \%\end{array}$ & $\begin{array}{c}52 \\
29.4 \%\end{array}$ & 0 & 177 & $\begin{array}{c}74 \\
41.8 \%\end{array}$ & $\begin{array}{c}93 \\
52.5 \%\end{array}$ & $\begin{array}{c}10 \\
5.6 \%\end{array}$ & 0 & 177 \\
\hline
\end{tabular}

$*<0.1$ No reliable protection. Booster injection is recommended. $0.1-0.5$ Reliable protection. Booster injection results in long term protection. $>0.5-1.1$ Reliable protection. Booster injection in $2-5$ years. $>1.1-5.0$ Reliable protection. Booster injection in 5 - 10 years. $>5.0$ Reliable protection. Booster injection in approx. 10 years. ${ }^{* *}<0.1$ No reliable protection. Booster injection is recommended. $0.1-1.0$ Reliable protection. Booster injection results in long term protection. $>1.0-1.5$ Reliable protection. Booster injection in 5 years. >1.5 - 2.0 Reliable protection. Booster injection in 7 years. $>2.0$ Reliable protection. Booster injection in approx. 10 years. 
the last dose of vaccine $(\mathrm{p}<0.001)$.

Fisher's exact test also didn't find a meaningful difference between antidiphtheria antibody levels and different age groups (40 - 60 years vs. above 60 years) $(\mathrm{p}=0.156)$. Meanwhile, among people with diphtheria antibody levels less than 0.1 (74 cases), 18 (24.3\%) had complete history of childhood vaccination and $56(75.6 \%)$ had unknown history. According to the chi-square test, there was a significant difference between the number of non immune cases and the history of childhood diphtheria-tetanus vaccination $(\mathrm{p}<0.001)$. Similarly, among those with antibody level against diphtheria less than $0.1,3$ people received vaccine during the past $5-10$ years and 71 cases $(95.9 \%)$ received a booster dose more than 10 years and in accordance with chi-square test, a significant difference was noted between no immunity to diphtheria and the time of receiving the last dose of vaccine $(\mathrm{p}<0.001)$.

In the urban population of the study, tetanus antibody levels less than $0.1,0.1$ - 0.5 and 0.5 - 5 were detected in 58 (45\%), 33 (25.6\%) and 38 (29.5\%) people, respectively. In the rural population, the level of anti-tetanus antibody less than 0.1 was detected in 25 (52.1\%), $0.1-0.5$ in 9 (18.8\%) and 0.5 - 5 in 14 cases (29.2\%), which showed no significant difference based on Fisher's exact test ( $\mathrm{p}=$ $0.623)$. The figures for anti-diphtheria antibody levels in urban population were 53 (41.1\%) less than 0.1, 70 cases (54.3\%) $0.1-1$ and 6 people (4.7\%) 1 - 2. In 48 cases of rural population, 21 (43.8\%) had anti-diphtheria antibody levels less than $0.1,23(47.9 \%)$ had $0.1-1$ and in 4 people (8.3\%) the level was $1-2$. Again, no statistically difference was found $(\mathrm{p}=0.511)$.

Except for known immunosuppression that was an exclusion criteria, 59 people (33.3\%) had an underlying disorder and 118 (66.7\%) had no underlying disease. Out of these, 34 persons (19.2\%) had diabetes mellitus and 25 (14\%) suffered from other disorders including high blood pressure, ischemic heart disease, liver or kidney dysfunction and so. Accordingly, tetanus antibody level was less than 0.1 in 23 (39\%), $0.1-0.5$ in 13 (22\%) and 0.5 - 5 in 23 (39\%). These figures for 118 subjects without underlying disease were 60 (50.8\%), $29(24.6 \%)$ and $29(24.6 \%)$ cases, respectively. According to Fisher's exact test, no significant correlation was found between antibody titers against tetanus and any underlying disease $(\mathrm{p}=0.123)$. Anti-diphtheria antibody levels were $<0.1,0.1-1$ and 1 2 in $27(45.8 \%), 28(47.5 \%)$ and $4(6.8 \%)$ subjects with an underlying disorder and $47(39.8 \%), 65(55.1 \%)$ and $6(5.1 \%)$ people without underlying disease, respectively. Again, no correlation was noted between the levels of anti-diphtheria antibody and an underlying disease $(\mathrm{p}=0.587)$.

\section{Discussion}

Despite widespread immunization of infants and children since the 1940s, tetanus still occurs in many parts of the world. Currently, in countries where tetanus vaccination is routine at birth, it primarily affects older adults because of their higher rate of being unvaccinated or of being inadequately vaccinated. 
Efficacy of the tetanus toxoid has never been studied in vaccine trial. It can be inferred from protective antitoxin levels that a complete tetanus toxoid series has a clinical efficacy of virtually $100 \%$; cases of tetanus occurring in fully immunized persons whose last dose was within the last 10 years are extremely rare [5]. Antitoxin levels decrease with time. While some persons may be protected for life, by 10 years after the last dose, most persons have antitoxin levels that only approach the minimal protective level. As a result, routine boosters are recommended every 10 years [5]. It is well-known that the immune system is partially immature at birth, resulting in a deficiency of cellular and humoral immunity. Therefore, neonatal immunization does not generally lead to rapid antibody responses, but it may result in efficient immunologic priming which can act as a basis for future responses. Accordingly, immunogenicity of DTwP vaccine was reported at a higher frequency following administration of the booster dose compared to the primary course [6]. However, the duration of immunity after vaccination against tetanus is controversial, and recommendations on revaccination against tetanus may not be valid unless they are based on studies of the duration of immunity in the population concerned [7].

The World Health Organization (WHO) recommends that nations should document the level of vaccine-induced immunity among children, adolescents and adults. Such information is needed to assess the susceptibility of populations to diphtheria and tetanus in countries without epidemic spread of the disease and to determine the epidemiological effect of widespread vaccination in developing countries [8]. Documentation of inadequate levels of antitoxin in a large proportion of the adult population in North America and Western Europe has caused great concern that a toxigenic strain introduced into these populations could cause an outbreak of disease similar to that in the former Soviet Union [9].

Studies conducted to investigate immunity status to tetanus and diphtheria in different parts of the world

Numerous studies have examined the adequacy of protection against tetanus and diphtheria in different parts of the world. Most of them have concluded that a significant proportion of the adult population have inadequate protection against tetanus and diphtheria. This is especially prevalent among elderly population. Serologic analysis of 18045 serum samples from the US population (6 years of age or older) during a 6-years period suggests that tetanus immunity wanes with age. Although $80 \%$ of patients aged 6 to 39 years were noted to have protective antibodies to tetanus, only $28 \%$ of patients older than 70 years were seropositive (29.5\% for diphtheria and $31.0 \%$ for tetanus) [10]. In another study by Choi et al. that conducted on Korean adults over the age of $40 \mathrm{yr}$, more than $90 \%$ of the study population had antibody levels against tetanus and about $45 \%$ had antibody levels against diphtheria, with concentrations of less than 0.1 $\mathrm{U} / \mathrm{mL}$. They also showed that the mean antibody levels of diphtheria and tetanus were inversely related with age [11]. Kulkarni et al. screened 62 male subjects for assessing the immunogenicity of Td vaccine. Mean age was 45 years ( \pm 7.7 years). 
At baseline, $12 \%$ of the subjects did not have adequate protection against diphtheria $(<0.1 \mathrm{IU} / \mathrm{mL})$ and only $9 \%$ had long-term protection $(\geq 1 \mathrm{IU} / \mathrm{mL})$. For tetanus, all of them had sufficient protection $(\geq 0.1 \mathrm{IU} / \mathrm{mL})$, but only $74 \%$ had long-term protection ( $\geq 1 \mathrm{IU} / \mathrm{mL}$ ) [12]. Ergönül et al. found poor immunity against tetanus among adults in Turkey. In their study, only $35.7 \%$ of individuals aged $>50 \mathrm{y}$ of age were found to be protected against tetanus [13]. Several other studies from Turkey demonstrated similar results [14] [15] [16] and suggested vaccination programs directed at the adult population should be developed [17]. Another study from Egypt revealed that the majority $(68.3 \%)$ of population from 2 months to 50 years had a protective level of IgG against tetanus. However, the level of susceptibility increases with age until it reaches $90.3 \%$. Authors suggest that monitoring immunization status and administering the tetanus vaccine as required are essential to insure adequate and long-lasting antibody levels [18].

On the other hand, the study conducted by Matousková et al. in the elderly in the Czech Republic revealed good immunity (91\%) against tetanus among the elderly in the Czech Republic as a result of a rich immunization history in this country [19]. Similarly, Gonçalves et al. suggested that, to protect against tetanus, there is no need to administer decennial boosters to the Portuguese adults who have complied with the childhood/adolescent schedule [20].

With regard to the difference between tetanus and diphtheria antibody levels and sex, only Klouche et al. reported an obvious sex dependency of the demonstrated inadequacy of immunological protection against tetanus. They found an inadequate protection (titer $<0.1 \mathrm{IU} / \mathrm{mL}$ ) in $107(15.5 \%)$, of whom $75(70 \%)$ were females. Women aged 20 years and above also had significantly lower average antitoxin titers than men (1.7 vs. $3.5 \mathrm{IU} / \mathrm{mL}$; $\mathrm{p}<0.0001)[21]$.

It is generally accepted that when more than $30 \%$ of a population are unprotected against diphtheria there is a risk of epidemic diphtheria occurring in that population [8]. The recent epidemics in Eastern Europe serve as a warning that diphtheria may re-emerge in susceptible populations. After the recent diphtheria epidemics in Eastern Europe in the early 1990s, Aue et al. re-evaluated the diphtheria and tetanus immunity of German blood donors. Their study revealed a questionable protection (antitoxin levels of 0.1 - $1.0 \mathrm{IU} / \mathrm{mL}$ ) against diphtheria among all blood donors in the study. The evaluation of tetanus immunity revealed only $0.5 \%$ of the subjects with no protection and $9.1 \%$ with questionable protection. They conclude that the diphtheria epidemics only lead to an insufficient improvement of the immunization status in a healthy German population [22]. In another study by Zasada et al., anti-diphtheria IgG was measured in 1387 serum samples from individuals aged 1 month to 85 years. They showed that 547 (39.4\%) people had anti-diphtheria toxoid IgG antibody levels below 0.1 $\mathrm{IU} / \mathrm{mL}(36.9 \% \leq 18$ years and $40.5 \%>18$ years old, respectively) and 212 (50.8\%) children and $542(55.9 \%)$ adults had only basic protection (0.1 - 1.0 $\mathrm{IU} / \mathrm{mL}$ ) and needed immediate booster [23]. According to the $30 \%$ prevalence of full protection against diphtheria in blood donors (18 - 61 years) in Rio de Ja- 
neiro, Damasco et al. suggested that immunity to diphtheria among healthy Brazilian adults is inadequate [8].

Studies conducted to investigate immunity status to tetanus and diphtheria in Iran

A study by Eslamifar et al. on 530 consecutive blood donor samples from Iranian people showed that $99.6 \%$ and $96 \%$ of subjects had protective levels of diphtheria and tetanus antibody, respectively. They stated that the high protective level of immunity to diphtheria and tetanus in Iran can be due to widespread use of booster vaccines in Iranian high schools and during the military services or for women in their pregnancy [24]. Saffar et al. also showed that among 110 Iranian mothers, susceptibility to diphtheria in unvaccinated mothers was $27 \%$, but all unvaccinated mothers except one were serologically immune to tetanus [25]. On the contrary, in the study conducted by Razzaghi et al. among 180 participants older than 59 years, only $30(16.7 \%)$ had protective tetanus antitoxin levels $(\geq 0.11 \mathrm{IU} / \mathrm{mL})$, and $34(18.9 \%)$ had protective antitoxin levels without the need of an immediate booster $\geq 0.51 \mathrm{IU} / \mathrm{mL}$. They suggested that most 50 years of age and older adults do not have protective levels of tetanus antitoxin because of inadequate vaccination coverage [26]. Similarly, the present study also found no immunity (antibody level $<0.1 \mathrm{IU} / \mathrm{mL}$ ) to tetanus and diphtheria toxins in $46.9 \%$ and $41.8 \%$ of adults aged $\geq 40$ years, respectively.

\section{Conclusion}

Widespread immunization of newborns and infants and mandatory booster doses of vaccine in certain age groups result in high levels of protective antibody against diphtheria and tetanus. However, ignoring the importance of receiving these booster doses in vast majority of adults could result in their lack of immunity. It seems rational to schedule a mandatory booster dose of tetanusdiphtheria vaccine for elder adults admitted to hospital for any reason, provided that they do not have a history of recent vaccination.

\section{References}

[1] Moradi-Lakeh, E.A. (2013) National Immunization Program in Iran: Whys and Why Nots. Human Vaccines \& Immunotherapeutics, 9, 112-114. https://doi.org/10.4161/hv.22521

[2] Kroger, A.T., Pickering, L.K., Wharton, M., Mawle, A., Hinman, A.R. and Orenstein, W.A. (2015) Immunization. In: Bennett, J.E., et al., Eds., Mandell, Douglas, and Bennett's Principles and Practice of Infectious Diseases, 8th Edition, Saunders, 3542 .

[3] Centers for Disease Control and Prevention (2012) Updated Recommendations for Use of Tetanus Toxoid, Reduced Diphtheria Toxoid, and Acellular Pertussis Vaccine (Tdap) in Pregnant Women-Advisory Committee on Immunization Practices (ACIP). Morbidity and Mortality Weekly Report, 62, 131-135.

[4] Vouking, M.Z., Tadenfok, C.N. and Ekani, J.M.E. (2017) Strategies to Increase Immunization Coverage of Tetanus Vaccine among Women in Sub Saharan Africa: A Systematic Review. Pan African Medical Journal, 27, 2. 
https://doi.org/10.11604/pamj.supp.2017.27.3.11535

[5] http://www.cdc.gov/vaccines/pubs/pinkbook/downloads/tetanus.pdf

[6] Zarei, S., Jeddi-Tehrani, M., Akhondi, M.M., Zeraati, H., Foroughalsadat, P., Ostadkarampour, M., Tavangar, B. and Shokri, F. (2009) Primary Immunization with a Triple Diphtheria-Tetanus-Whole Cell Pertussis Vaccine in Iranian Infants: An Analysis of Antibody Response. Iranian Journal of Allergy, Asthma and Immunology, 8, 85-93.

[7] Meira, A.R. (1973) Duration of Immunity after Tetanus Vaccination. The Lancet, 302, 659-661. https://doi.org/10.1016/S0140-6736(73)92490-2

[8] Damasco, P.V., Pimenta, F.P., Filardy, A.A., Brito, S.M., Andrade, A.F., Lopes, G.S., Hirata Jr., R. and Mattos-Guaraldi, A.L. (2005) Prevalence of IgG Diphtheria Antitoxin in Blood Donors in Rio de Janeiro. Epidemiology and Infection, 133, 911-914. https://doi.org/10.1017/S0950268805003997

[9] MacGregor, R.R. (2015) Corynebacterium Diphtheria (Diphtheria). In: Bennett, J.E., et al., Eds., Douglas, and Bennett's Principles and Practice of Infectious Diseases, 8th Edition, Saunders, 2371.

[10] McQuillan, G., Kruszon-Moran, D., Deforest, A., Chu, S. and Wharton, M. (2002) Serologic Immunity to Diphtheria and Tetanus in the United States. Annals of Internal Medicine, 136, 660-666. https://doi.org/10.7326/0003-4819-136-9-200205070-00008

[11] Choi, J., Choo, E., Huh, A., Choi, S., Eom, J., Lee, J., Park, S. and Kang, J. (2010) Immunogenicity and Safety of Diphtheria-Tetanus Vaccine in Adults. Journal of Korean Medical Science, 25, 1727-1732.

[12] Kulkarni, P., Raut, S., Dhorje, S., Barde, P., Koli, G. and Jadhav, S. (2011) Diphtheria, Tetanus, and Pertussis Immunity in Indian Adults and Immunogenicity of $\mathrm{Td}$ Vaccine. ISRN Microbiology, 2011, Article ID: 745868. https://doi.org/10.5402/2011/745868

[13] Ergönül, O., Sözen, T. and Tekeli, E. (2001) Immunity to Tetanus among Adults in Turkey. Scandinavian Journal of Infectious Diseases, 33, 728-730. https://doi.org/10.1080/003655401317074491

[14] Dundar, V., Yumuk, Z., Ozturk-Dundar, D., Erdoğan, S. and Gacar, G. (2005) Prevalence of Tetanus Immunity in the Kocaeli Region, Turkey. Japanese Journal of Infectious Diseases, 58, 279-282.

[15] Cavuslu, S., Oncul, O., Altunay, H., Ozsoy, M.F. and Kocak, N. (2003) Seroprevalence of Tetanus Antibody in Turkish Population and Effectiveness of Single-Dose Tetanus Toxoid. European Journal of Clinical Microbiology \& Infectious Diseases, 22, 431-433.

[16] Coplu, N., Esen, B., Gozalan, A., Miyamura, K., Yoshida, I., Kurtoglu, D., Dogan, N.O., Afacan, G., Unal, A., Ishida, S. and Takahashi, M. (2004) Tetanus Antibody Assay Combining In-House ELISA and Particle Agglutination Test and Its Serosurvey Application in a Province in Turkey. Japanese Journal of Infectious Diseases, 57, 97-102.

[17] Oztürk, A., Göahmetoğlu, S., Erdem, F. and Mýsgüroğlu Alkan, S. (2003) Tetanus Antitoxin Levels among Adults over 40 Years of Age in Central Anatolia, Turkey. Clinical Microbiology and Infection, 9, 33-38. https://doi.org/10.1046/j.1469-0691.2003.00469.x

[18] Redwan, El-R.M. and Al-Awady, M.K. (2002) Prevalence of Tetanus Immunity in the Egyptian Population. Human Antibodies, 11, 55-59. 
[19] Matousková, I., Máchová, L., Cízek, L., Janoutová, G., Hosková, J. and Janout, V. (2007) Tetanus Immunity in the Elderly in the Czech Republic. Epidemiologie, Mikrobiologie, Imunologie, 56, 10-13.

[20] Gonçalves, G., Santos, M.A., Frade, J.G. and Cunha, J.S. (2007) Levels of Diphtheria and Tetanus Specific IgG of Portuguese Adult Women, before and after Vaccination with Adult Type Td. Duration of Immunity Following Vaccination. BMC Public Health, 7, 109-120. https://doi.org/10.1186/1471-2458-7-109

[21] Klouche, M., Gorg, S., Wilhelm, D. and Kirchner, H. (1994) Sex and Age Dependent Gaps in Tetanus Immunization. Deutsche Medizinische Wochenschrift, 119, 827-832. https://doi.org/10.1055/s-2008-1058767

[22] Aue, A., Hennig, H., Krüger, S., Closius, B., Kirchner, H. and Seyfarth, M. (2003) Immunity against Diphtheria and Tetanus in German Blood Donors. Medical Microbiology and Immunology, 192, 93-97.

[23] Zasada, A., Rastawicki, W., Rokosz, N. and Jagielski, M. (2013) Seroprevalence of Diphtheria Toxoid IgG Antibodies in Children, Adolescents and Adults in Poland. BMC Infectious Diseasees, 13, 551. https://doi.org/10.1186/1471-2334-13-551

[24] Eslamifar, A., Ramezani, A., Banifazl, M., Sofian, M., Mahdaviani, F., Yaghmaie, F., et al. (2014) Immunity to Diphtheria and Tetanus among Blood Donors in Arak, Central Province of Iran. IJM, 6, 190-193.

[25] Saffar, M.J., Khalilian, A.R., Ajami, A., Saffar, H. and Qaheri, A. (2008) Seroimmunity to Diphtheria and Tetanus among Mother-Infant Pairs; The Role of Maternal Immunity on Infant Immune Response to Diphtheria-Tetanus Vaccination. Swiss Medical Weekly, 138, 256-260.

[26] Razzaghi, R., Khalifesoltani, A., Heravi, M.M. and Akbari, H. (2011) Tetanus Immunity in Individuals Aged 50 Years or Older in Kashan, Iran. Acta Medica Iranica, 49, 379-382. 